\title{
Die SGUM/SSUM Gratuliert
}

\section{SVUPP und Hüftkommission}

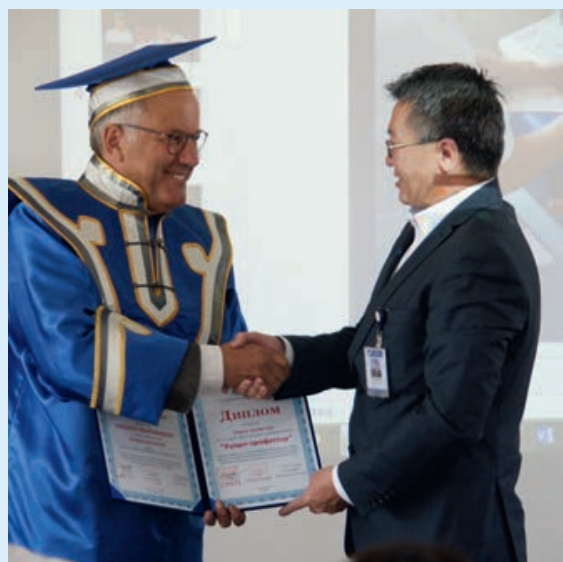

Prof. h. c. Thomas Baumann erhält von Prof. Enkhtur Shonkhuuz, dem Direktor des National Center for Maternal and Child Health in Ulaanbaatar die Urkunde zur Ernennung des Ehrenprofessors überreicht (Foto: Michael Büttcher).

Im Namen der SVUPP (Sektion Pädiatrie der SGUM) und der Schweizerischen Hüftkommission

Die beiden Schweizer Praxispädiater Thomas Baumann, Solothurn und Raoul Schmid, Baar erhielten in der Mongolei, am National Center for Maternal and Child Health in Ulaanbaatar, den Titel eines Ehrenprofessors verliehen. Damit werden die Verdienste der beiden Gründer des Swiss-Mongolian Pediatric Projects honoriert.

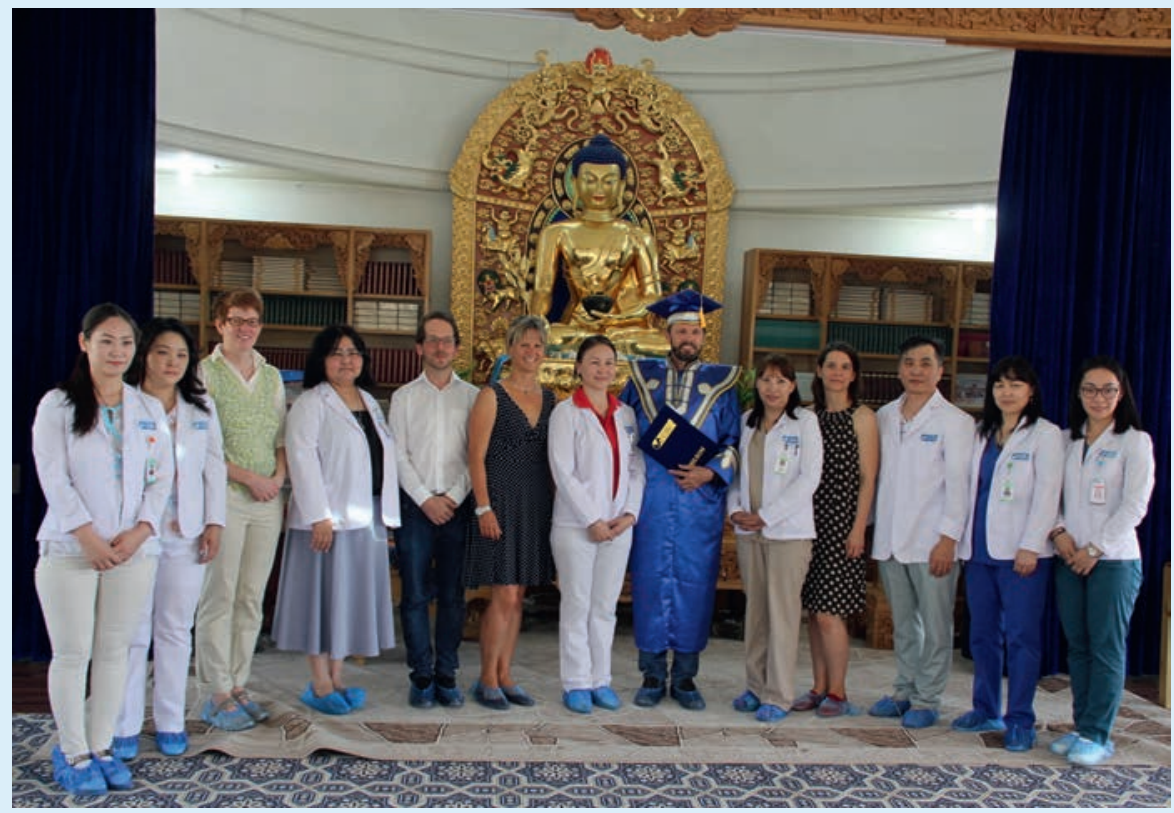

Prof. h.c. Raoul Schmid und ein Teil des SMOPP-Teams bei der Ehrungsfeier (Foto: Corinne Wyder).

Dieses Projekt kümmert sich seit 10 Jahren um die Ultraschall-Früherkennung und die konservative Behandlung der Hüftdysplasie, der häufigsten angeborenen und potenziell invalidisierenden Entwicklungsstörung des Bewegungsapparates. Dies geschieht mittels Wissenstransfer und Materiallieferungen im Hinblick auf ein landesweites Präventivprogramm. Das Projekt wird wissenschaftlich begleitet und evalu- iert, eine permanente internetbasierte Qualitätskontrolle ermöglicht den kontinuierlichen Support.

Die in der Schweiz domizilierte Hilfsorganisation finanziert sich ausschliesslich über Spenden. Infos unter www.smopp.ch. 